\title{
Pelatihan penggunaan buku panduan pembuatan dan pelaksanaan pembelajaran di taman lalu lintas untuk guru taman kanak-kanak
}

\author{
Eka Sapti Cahya Ningrum, Martha Christianti, Ika Budi Maryatun, Nur Cholimah \\ Pendidikan Anak Usia Dini, FIP, Universitas Negeri Yogyakarta \\ Jalan Colombo No 1 Yogyakarta, Indonesia \\ E-mail: eka_sapticn@uny.ac.id
}

\begin{tabular}{ll}
\hline \hline ARTICLE INFO & ABSTRACT \\
\hline \hline Article & Tujuan pengabdian ini adalah untuk meningkatkan kemampuan para guru dalam \\
history: & membuat dan melaksanakan pembelajaran di taman lalu lintas untuk taman \\
Received:28-04-2020 & kanak-kanak di Daerah Istimewa Yogyakarta. Pemecahan masalah yang \\
Revised: 05-05-2020 & dilakukan bertujuan untuk meningkatkan pengetahuan tentang: (1) rambu lalu \\
Accepted: 12-05-2020 & lintas yang harus ada dalam taman lalu lintas, (2) etika berlalu lintas yang harus \\
& dikenalkan pada anak usia dini, (3) cara membuat taman lalu lintas di sekolah, \\
Keywords: & (4) cara merancang pembelajaran di taman lalu lintas, (5) cara melaksanakan \\
pelatihan, pembelajaran, & pembelajaran di taman lalu lintas dalam bentuk praktik microteaching dan \\
taman lalu lintas, guru tk & pendampingan, dan (6) pembuatan video praktik pembelajaran di taman lalu \\
& lintas. Pelatihan penggunaan buku panduan pembuatan dan pelaksanaan \\
& pembelajaran di taman lalu lintas untuk taman kanak-kanak bagi guru TK di DIY \\
& ini mencapai target yang diharapkan yaitu kehadiran peserta melebihi target, \\
& yaitu dari target 25 peserta menjadi 35 peserta. Selain itu, para guru dapat \\
& menggunakan taman lalu lintas dalam pembelajaran di sekolah, mengenalkan \\
& rambu lalu lintas dan etika berlalu lintas pada anak melalui penjelasan dengan \\
& gambar dan praktik langsung dengan bermain peran, serta mengajak anak untuk \\
& belajar di taman lalu lintas dalam tema pembelajaran yang lain seperti pekerjaan \\
dan lingkungan.
\end{tabular}

\begin{abstract}
The purpose of this service is to improve the ability of teachers to create and implement learning in traffic parks for kindergartens in Daerah Istimewa Yogyakarta. The problem solving aims to increase knowledge about: (1) traffic signs that must exist in a traffic park, (2) traffic ethics that must be introduced in early childhood, (3) how to create a traffic park at school, (4) how to design learning in a traffic park, (5) how to carry out learning in a traffic park in the form of microteaching and mentoring practices, and (6) making a video of learning practices in a traffic park. The training on the use of manuals for the preparation and implementation of learning in traffic parks for kindergartens for kindergarten teachers in DIY reached the expected target, namely the presence of participants exceeding the target, from the target of 25 participants to 35 participants. In addition, teachers can use traffic parks in learning at school, introduce traffic signs and traffic ethics to children through explanations with pictures and hands-on practice by playing roles, and invite children to learn in traffic parks in other learning themes like work and the environment.
\end{abstract}

\section{PENDAHULUAN}

Pada saat ini karakter menjadi salah satu prioritas mendasar dalam pendidikan anak usia dini. Persoalan karakter telah menjadi permasalahan bersama. Pemerintah khususnya Kementerian Pendidikan dan Kebudayaan yang terdiri atas delapan belas karakter yang dikembangkan, yaitu: religius, jujur, toleransi, disiplin, kerja keras, kreatif, mandiri, demokratis, rasa ingin tahu, semangat kebangsaan, cinta tanah air, menghargai prestasi, bersahabat/komunikatif, cinta damai, gemar membaca, peduli lingkungan, peduli sosial, dan tanggung jawab. (https://www.paud.id/2015/08/18-nilai-pendidikankarakter-di-sekolah.html, diakses 6 April 2020). 
Jurnal Pendidikan Anak, Volume 9 (1), Tahun 2020

Eka Sapti Cahya Ningrum, Martha Christianti, Ika Budi Maryatun, Nur Cholimah

Salah satu nilai yang penting ditanamkan sejak dini adalah kedisiplinan sebagai upaya untuk mempersiapkan bagi kehidupan anak pada saat dewasa kelak. Penanaman nilai kedisiplinan merupakan tanggung jawab bersama. Hal tersebut dilandasi oleh pentingnya dukungan semua pihak. Tanpa komitmen bersama sangatlah sulit untuk menanamkan dalam diri anak karena bukan sekedar dipelajari, namun juga diterapkan dalam kehidupan sehari-hari. Lebih lanjut, penanaman kedisiplinan merupakan upaya penanaman kesadaran melalui aturan dan bimbingan agar anak usia dini dapat memiliki sikap dan perilaku tertib terhadap aturan dan ketentuan yang ada.

Salah satu perilaku disiplin yang hingga saat ini masih rendah khususnya di kalangan pelajar atau remaja di Indonesia adalah dalam berlalu lintas. Perilaku berlalu lintas masih belum baik ditandai dengan masih tingginya kecelakaan lalu lintas pada kalangan remaja khususnya pelajar. Hal tersebut beralasan karena sesuai data yang ada dalam beberapa tahun terakhir kejadian kecelakaan lalu lintas didominasi oleh kecerobohan atau rendahnya kedisiplinan pengguna jalan. Kecelakaan lalu lintas dari tahun- ke tahun menunjukkan adanya peningkatan yang mengkhawatirkan sehingga perlu penanganan yang serius. Data kecelakaan di DIY dalam beberapa tahun disajikan pada Tabel 1 berikut.

Tabel 1. Data kecelakaan lalu lintas di DIY

\begin{tabular}{|c|c|c|c|c|c|}
\hline \multirow{2}{*}{ Sub Elemen } & \multicolumn{5}{|c|}{ Tahun } \\
\hline & 2016 & 2017 & 2018 & 2019 & 2020 \\
\hline 3 & 4 & 5 & 6 & 7 & 8 \\
\hline \multicolumn{6}{|l|}{ Data Kecelakaan Lalu Lintas } \\
\hline Jumlah Kecelakaan & $3.777,00$ & $4.011,00$ & $5.061,00$ & $5.381,00 *$ & \\
\hline Korban Meninggal Dunia & 464,00 & 442,00 & 485,00 & $387,00 *$ & \\
\hline Korban Luka Ringan & $4.910,00$ & $5.040,00$ & $6.800,00$ & $6.564,00 *$ & \\
\hline Korban Luka Berat & 21,00 & 29,00 & 23,00 & $8,00 *$ & \\
\hline Kerugian Materi & $2.217 .788 .000,00$ & $2.382 .120 .300,00$ & $406.952 .975 .000,00$ & $2.700 .461,000,00 *$ & \\
\hline \multicolumn{6}{|l|}{ Data Pelanggaran Lalu Lintas } \\
\hline Jumlah Pelanggaran & $80.922,00$ & $154.472,00$ & $404.250 .000,00$ & $166.501,00 *$ & \\
\hline
\end{tabular}

Sumber: http://bappeda.jogjaprov.go.id/dataku/data_dasar/index/548-data-kecelakaan-danpelanggaran-lalu-lintas?id_skpd=39 diakses 7 April 2020

Upaya penanaman kesadaran berlalu lintas pada anak usia dini menjadi sebuah keharusan. Upaya tersebut merupakan salah satu langkah strategis untuk memberikan kesadaran akan perilaku dan etika berlalu lintas dengan baik. Bentuk program pengenalan, pelatihan, pembiasaan, dan pendampingan harus dilakukan dengan baik oleh guru, sehingga guru harus dilibatkan secara aktif untuk memaksimalkan pencapaian tujuan tersebut. Guru perlu dibekali dengan pengetahuan dan kompetensi untuk membuat dan melaksanakan pembelajaran khususnya taman lalu-lintas untuk membangun kepribadian disiplin dalam berlalu lintas dalam diri anak.

Pada beberapa taman kanak-kanak materi berlalu lintas masih menjadi aktivitas ekstrakurikuler, padahal mereka memiliki lahan yang memadai dan kesiapan guru yang baik pula. Anak usia dini sebagai calon penerus generasi yang akan datang membutuhkan media untuk belajar dan berkembang. Sementara itu, pengetahuan semua guru belumlah komprehensif untuk memaksimalkan pembelajaran yang dilakukan atau baru sebagian guru yang memiliki kemampuan untuk aktivitas pendidikan yang memadai. 
Jurnal Pendidikan Anak, Volume 9 (1), Tahun 2020

Eka Sapti Cahya Ningrum, Martha Christianti, Ika Budi Maryatun, Nur Cholimah

\section{METODE}

Langkah-langkah dalam penyelesaian masalah dalam pengabdian ini dapat disajikan pada gambar berikut.

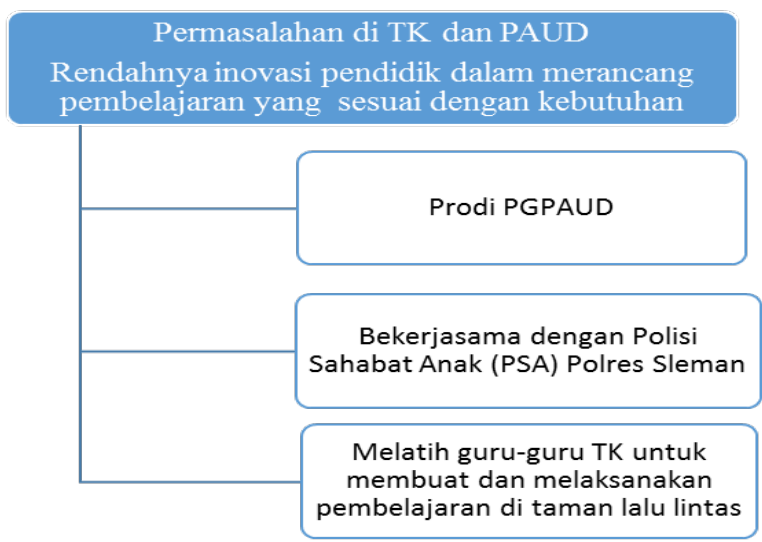

Gambar 1. Langkah-langkah penyelesaian masalah

Pelaksanaan pengabdian masyarakat ini dilakukan di TK mitra Jurusan PAUD. TK Mitra ini terdiri tujuh TK yang digunakan untuk Program Praktik Lapangan (PPL) program PPG (Pendidikan Profesi Guru), tujuh TK yang digunakan Program Latihan Terbimbing (PLT) mahasiswa reguler, dan enam TK yang ada di sekitar UNY.

Adapun TK Mitra yang digunakan untuk PPL PPG yaitu:

1. TK Masjid Syuhada,

2. TK ABA Nitikan,

3. TK Negeri Pembina Bantul,

4. TKIT BAIK,

5. TK Pedagogia,

6. TKIT Alhamdulillah,

7. TK Pembina Kota Yogyakarta.

Sedangkan TK mitra PLT mahasiswa reguler yaitu:

1. TK PKK 18 Harapan Bangsa,

2. TK TAT TWAM ASI,

3. TK ABA LABBAIK AP III,

4. TK ABA Sutopadan,

5. TK Dharma Bakti IV,

6. TK ABA Godegan,

7. TK Madukismo.

Sedangkan TK yang berada di sekitar UNY yaitu:

1. TKIT An-Nuur,

2. TK Hamemayu,

3. TK ABA Potorono,

4. TK BMD Pandeansari,

5. TK ABA Jogokaryan,

6. TKIT Salman Al Farizi. 
Jurnal Pendidikan Anak, Volume 9 (1), Tahun 2020

Eka Sapti Cahya Ningrum, Martha Christianti, Ika Budi Maryatun, Nur Cholimah

\section{HASIL DAN PEMBAHASAN}

\section{Hasil}

Kegiatan pengabdian dilaksanakan selama tiga hari yaitu pada tanggal 9 Juli 2019, 24 Juli 2019, dan satu hari tertentu disesuaikan dengan sekolah untuk mempraktikkan kegiatan pembelajaran di taman lalu lintas. Berikut ini penjelasan masing-masing sesi dalam dua hari.

1. Selasa, 9 Juli 2019

Sesi 1 berisi paparan penjelasan tentang taman lalu lintas untuk taman kanak-kanak oleh Ika Budi Maryatun, M.Pd. Dalam paparan dijelaskan apa itu taman lalu lintas, manfaatnya, dan jenisnya. Dilanjutkan sesi 2 berupa pemaparan tentang rambu lalu lintas dan etika berlalu lintas yang disampaikan oleh Polisi Sahabat Anak dari Polres Sleman. Kemudian sesi 3 diisi dengan pelatihan merancang pembuatan taman lalu lintas.

2. Rabu 24 Juli 2019

Sesi 4 diisi dengan paparan pembelajaran di taman lalu lintas oleh Nur Cholimah, M.Pd. Pembelajaran di taman kanak-kanak yang bisa dilakukan di taman lalu lintas tidak hanya untuk mengenalkan tentang rambu dan etika berlalu lintas, namun banyak tema dan kegiatan pembelajaran juga bisa dilakukan di taman lalu lintas. Selanjutnya sesi 5 diisi dengan pelatihan membuat perencanaan pembelajaran di taman lalu lintas. Sesi 6 merupakan sesi koordinasi dosen pelaksana dengan sekolah tempat mempraktikkan kegiatan pelatihan selama dua hari tersebut. Masing-masing berkoordinasi dan menentukan hari praktik pembelajaran di taman lalu lintas dengan anak dalam pembelajaran agar dapat dipantau oleh dosen pendamping. Pada tahap selanjutnya dilakukan pendampingan pada masing-masing peserta pelatihan untuk memastikan keberhasilan pelaksanaan program, sekaligus mengatasi permasalahan yang mungkin dihadapi oleh para guru.

Secara rinci, pelaksanaan pembelajaran lalu lintas di masing-masing TK yaitu sebagai berikut.

1. TK Al-I'dad An-Nuur

a. Pembukaan dan pengenalan pembelajaran lalu lintas

Dalam pembelajaran lalu lintas di TK Al-I'dad An-Nur yang dikenalkan terlebih dahulu kepada anak yaitu mengenai keselamatan berkendara yang meliputi menggunakan helm, jaket, kacamata dan berdoa sebelum bepergian. Dan untuk pengguna mobil harus menggunakan sabuk pengaman agar aman saat berkendara. Rambu-rambu yang dikenalkan meliputi lampu lalu lintas, rambu tidak diperbolehkan lewat, rambu larangan parkir, rambu petunjuk lampu lalu lintas, rambu petunjuk persimpangan empat, serta rambu parkir. Saat pengenalan lampu lalu lintas, guru menjelaskan jika lampu merah harus berhenti, lampu kuning jalan hati-hati, dan lampu hijau jaan pelan-pelan. Selain itu, saat pengenalan rambu tidak diperbolehkan lewat, guru menjelaskan jika melihat rambu seperti itu mungkin sedang ada acara atau memang tidak diperbolehkan lewat jalan tersebut. Rambu dilarang parkir biasanya berada di pinggir jalan, sehingga saat parkir harus melihat apakah daerah itu bisa untuk parkir atau tidak. Saat melihat rambu petunjuk lampu lalu lintas diminta hati-hati karena di depan akan ada lampu petunjuk lalu lintas. Jika sedang berkendara melihat ada rambu petunjuk persimpangan empat, diminta untuk hatihati karena jika terus saja berjalan bisa saja terjadi kecelakaan. Setelah mengenalkan rambu-rambu lalu lintas, guru menjelaskan tentang cara menyeberang jalan yang benar yaitu dengan tengok ke arah kiri kemudian tengok ke arah kanan kemudian tengok ke arah kiri lagi kemudian tengok ke arah kanan lagi dan jika jalan sepi, pejalan kaki baru bisa menyeberangi jalan. Setelah pembukaan dan pengenalan rambu lalu lintas selesai, guru meminta anak untuk praktik langsung dengan menggunakan sepeda roda tiga.

b. Praktik langsung

Sebelum praktik langsung dimulai, anak-anak mempersiapkan diri dengan ada yang jadi pengendara, ada yang jadi pejalan kaki, serta ada yang jadi polisi. Pengendara mempersiapkan diri dengan menggunakan helm dan sepeda roda tiga. Dan yang menjadi pejalan kaki menunggu di pinggir jalan. Saat praktik berlangsung, anak menyeberang tidak menggunakan zebra cross, anak-anak menyeberang secara bersamaan. Setelah pejalan kaki menyebrang pengendara melanjutkan perjalanan lagi. Saat praktik berlangsung, rambu yang diajarkan yaitu rambu petunjuk lampu lalu lintas, rambu lampu lalu lintas, rambu persimpangan empat, dan rambu belok kiri. Praktik langsung dilakukan sebanyak enam kali dengan pengendara yang berbeda. 
Jurnal Pendidikan Anak, Volume 9 (1), Tahun 2020

Eka Sapti Cahya Ningrum, Martha Christianti, Ika Budi Maryatun, Nur Cholimah

c. Kegiatan penutup

Pembelajaran lalu lintas ditutup dengan mengulas kembali rambu yang sudah diajarkan. Selain itu pengenalan sebab akibat juga dijelaskan, dan anak-anak istirahat.

2. TK ABA Nitikan

Taman lalu lintas di TK ABA Nitikan dibuat dihalaman luar yaitu pada halaman bermain anak. Pada taman lalu lintas TK ABA Nitikan jalan raya tiruannya dibuat permanen. Jalan tiruan yang dibut yaitu pertigaan, perempatan, jalan lurus dan sedikit berbelok dan dilengkapi dengan garis marka dan zebra cross, sedangkan rambu-rambu lalu lintas dibuat dari papan yang dapat dipindah-pindah. Rambu-rambu lalu lintas tersebut terdiri dari putar balik, dilarang berhenti, belok kiri, dilarang parkir, dilarang masuk, dilarang belok kanan, lampu lalu lintas, tempat penyeberangan jalan, dan parkir mobil.

Sebelum praktik di taman lalu lintas, anak-anak diperkenalkan dahulu dengan beberapa miniatur rambu laluintas dengan beberapa fungsinya, misalnya seperti lampu merah maka harus berhenti, lampu hijau maka jalan, dan lambu kuning artinya hati-hati. Selain itu, guru juga menyanyikan lagu tentang Polisi. Guru juga memberikan tepuk menyeberang agar anak-anak paham bahwa menyebrang harus tengok kanan kiri lalu setelah aman bisa menyeberang.

3. TK IT Alhamdulillah

TK IT Alhamdulillah sebelum masuk kelas, guru-guru menyambut peserta didik dengan bersalaman. Pijakan lingkungan main digunakan sebagai taman-lalu lintas dengan menggunakan banner yaitu bergambar jalan raya dan rerumputan. Jalan raya tersebut yaitu pertigaan, jalan lurus, bundaran yang dilengkapi dengan marka jalan dan zebra cross.

Pada awal pembelajaran atau pijakan sebelum main, guru membuka dengan pembukaan yaitu memberi salam, berdoa, tanya jawab seputar yang akan dipraktikan di taman lalu lintas. Guru juga menerangkan tentang safety saat berkendara, yaitu menggunakan helm saat berkendara dengan mengancing sampai berbunyi klik, selain itu juga bisa menggunakan pengaman siku. Guru juga memperkenalkan tentang rambu-rambu lalu lintas beserta artinya, misalnya rambu-rambu dengan huruf $\mathrm{P}$ yang dicoret artinya dilarang parkir, S dicoret artinya dilarang berhenti, huruf $\mathrm{P}$ artinya boleh parkir, tanda belok kanan yang dicoret artinya tidak boleh belok kanan, rambu-rambu dengan tulisan STOP, artinya dilarang berhenti, panah ke kiri artinya k kiri, panah ke kanan artinya ke kanan dan rambu-rambu lainnya. Selanjutnya guru mengajarkan tentang tepuk lalu lintas, yaitu saat lampu merah menyala maka kita harus berhenti, lampu hijau menyala maka kita bisa jalan dan lampu kuning menyala maka harus hati-hati dan siap untuk berhenti.

Pada sesi pijakan selama main atau praktik lalu lintas, peserta didik menggunakan helm untuk keamanan selama perjalanan. Saat praktik juga terdapat peserta didik yang berperan sebagai pak polisi yang mengatur jalan yaitu ketika di pertigaan yang terdapat traffic light, pak polisi memberhentikan kendaran saat lampu merah dan mempersilahkan untuk berjalan ketika lampu nyala hijau dengan meniupkan peluit. Peserta didik diajarkan untuk menyeberang pada zebra cross. Ketika terdapat tanda lingkaran yang terdapat setrip putih maka dilarang masuk.

Pada kegiatan penutup, guru membantu peserta didik untuk merilekskan diri dengan senam kecil sambil duduk untuk meredakan kelelahan, lalu menanyakan kembali (recalling) kegiatan yang telah dilakukan di taman lalu lintas, dan kemudian ditutup dengan berdoa.

\section{TK Pembina Yogyakarta}

Taman lalu lintas yang ada di TK tersebut terdapat halaman yang cukup untuk digunakan lintasan sepeda anak-anak, namun tidak terdapat garis marka jalan seperti jalan raya pada nyatanya. Selain itu, taman lalu lintas tersebut dilengkapi dengan beberapa rambu-rambu lalu lintas dari papan yang terletak di pinggir taman lalu lintas tersebut, namun rambu-rambu tidak diperlihatkan.

\section{TK Madukismo}

Guru dan anak duduk melingkar di karpet, yang berada di halaman sekolah. Guru melakukan apersepsi terlebih dahulu dengan berdoa dan menanyakan kabar. Guru juga melakukan tanya jawab seputar anggota tubuh yang merupakan tema pada hari itu. Pada pagi hari, guru juga mengenalkan rambu-rambu lalu lntas, diantaranya adalah: lampu APILL (Alat Pemberi Isyarat Lalu Lintas), tanda 
Jurnal Pendidikan Anak, Volume 9 (1), Tahun 2020

Eka Sapti Cahya Ningrum, Martha Christianti, Ika Budi Maryatun, Nur Cholimah

berhenti, tanda parkir dan dilarang parkir, tanda dilarang masuk, tanda arah jalan, dan tanda persimpangan jalan (pertigaan).

Usai mengenalkan rambu-rambu lalu lintas, guru mengajak anak untuk berdiri dan diajarkan “Tepuk Menyeberang”. Anak-anak kemudian diajak untuk praktik menjadi pengguna jalan di taman lalu lintas yang sudah dibuat dengan dicat pada halaman sekolah. Anak-anak terlihat sangat antusias, mereka praktik menggunakan sepeda sebagai kendaraannya. Anak-anak juga praktik menyeberang jalan dengan benar. Tidak hanya itu, anak-anak juga melakukan simulasi parkir dengan arahan guru. Semua anak mengikuti praktik yang diarahkan oleh guru.

Kegiatan ditutup dengan mengevaluasi kembali kegiatan praktik tadi dan me-recall tentang pengenalan rambu. Anak-anak dapat menyebutkan kembali rambu-rambu apa saja yang sudah dipelajarinya, dan anak-anak terlihat sangat antusias dengan kegiatan hari itu.

\section{TK Pedagogia}

Guru menjelaskan pentingnya keberadaan taman lalu lintas untuk generasi muda, karena dapat mengedukasi anak-anak tentang keselamatan berlalu lintas. Dan pengenalan sejak dini sangat penting karena sangat berpengaruh saat anak-anak sudah berada di jalan. Saat praktik berlangsung guru bertindak sebagai polisi lalu lintas dan anak-anak bertindak sebagai pengendara. Rambu yang diajarkan saat praktik yaitu lampu lalu lintas. Anak-anak bergantian melewati jalan dengan perintah guru.

\section{TK PKK 18 Harapan Bangsa}

\section{a. Pengenalan}

Guru menjelaskan mengenai rambu-rambu yang ada. Rambu yang dijelaskan meliputi rambu larangan parkir, rambu petunjuk lampu lalu lintas, rambu larangan berhenti, rambu untuk tempat menyeberang pejalan kaki. Saat menjelaskan lampu lau lintas, guru menjelaskan bahwa saat lampu berwarna merah pengendara harus berhenti, saat lampu berwarna kuning pengendara harus jalan hatihati, dan saat lampu berwarna hijau pengendara harus jalan pelan-pelan.

b. Praktik langsung

Saat praktik berlangsung guru lebih fokus pada praktik lampu lalu lintas, dengan mengganti warna-warna lampu saat anak dan guru berkendara. Rambu yang dipraktikkan yaitu rambu petunjuk lampu lalu lintas dan lampu lalu lintas. TK PKK 18 Harapan Bangsa ini kreatif dengan membuat sendiri lampu lalu lintas, dan guru bertugas mengganti warna-warna lampu. Saat praktik guru mengajarkan anak bagaimana cara menyeberang, dan anak menyeberang melalui zebra cross.

c. Kegiatan penutup

Dalam kegiatan penutup, anak diajarkan mengenai rambu parkir dan larangan berhenti. Anak diminta untuk parkir di tempat parkir dengan tertib.

\section{TK TAT TWAM ASI}

TK TAT TWAM ASI merupakan salah satu TK yang berada di Kecamatan Kasihan. Pada kesempatan kali ini TK TAT TWAM ASI memasukan materi mengenai pengenalan lalu lintas di salah satu pembelajarannya. Guru mengajaak anak berdisusi tanya-jawab mengenai cara menyebrang jalan dengan benar. Saat guru melontarkan pertanyaan "Apa yang pertama kali kita lakukan saat menyebrang jalan?”. Salah satu anak menjawabnya dengan benar “Tengok kanan-kiri!”. Setelah itu guru menjelaskan secara detail cara menyeberang jalan dengan benar dan anak-anak mendengarkannya dengan antusias.

Hasil pelatihan dan pendampingan menunjukkan bahwa jumlah kehadiran peserta melebihi target perencanaan yaitu 35 orang dari jumlah sasaran 25 orang guru. Peserta yang hadir sangat antusias mengikuti kegiatan dari awal sampai akhir. Pada saat praktik merancang taman lalu lintas dan membuat rencana pembelajaran di taman lalu lintas dalam kelompok, semua peserta dapat menghasilkan rancangan taman lalu lintas yang akan digunakan untuk pembelajaran disekolah dan menyusun RPPH (Rencana Program Pembelajaran Harian) untuk pembelajaran secara kelompok setiap TK. Temuan dalam pelatihan ini antara lain:

a. Guru-guru tidak memahami rambu lalu lintas yang wajib ada dalam pembelajaran untuk dikenalkan kepada anak. Ada tiga jenis rambu lalu lintas yang harus/wajib dikenalkan yaitu yang mempunyai warna dasar biru, merah dan kuning. 
Jurnal Pendidikan Anak, Volume 9 (1), Tahun 2020

Eka Sapti Cahya Ningrum, Martha Christianti, Ika Budi Maryatun, Nur Cholimah

b. Sebagian besar guru yang melakukan kesalahan dalam praktik pengenalan lalu lintas, karena ada beberapa etika berlalu lintas yang belum diketahui secara umum dalam kehidupan sehari-hari.

c. Sebagian besar guru masih belum tepat dalam menyusun RPPH.

Berdasarkan hasil pendampingan di sekolah diperoleh data bahwa guru-guru peserta pelatihan mampu:

a. Menggunakan hasil rancangan taman lalu lintas yang disusun dalam kegiatan pembelajaran dari pertemuan pagi hari hingga siang.

b. Menjelaskan dengan menunjukkan tanda rambu lalu lintas dan artinya dengan bahasa yang sederhana dan memberi contoh pada anak-anak bagaimana etika berlalu lintas yang tepat.

c. Melaksanakan pembelajaran di taman lalu lintas dengan kreatif dilihat dari antusias siwa dalam mengikuti pembelajaran.

d. Menegur anak terkait etika lalu lintas yang dilanggar atau belum muncul pada diri anak.

Berdasarkan penjelasan tersebut, maka dapat diketahui bahwa hasil pelatihan ini mencapai keberhasilan, baik dalam segi kualitas maupun kuantitas.

\section{Pembahasan}

Pelatihan Penggunaan Buku Panduan Pembuatan dan Pelaksanaan Pembelajaran di Taman Lalu Lintas untuk Taman Kanak-kanak bagi Guru TK di DIY mendapatkan pencapaian keberhasilan yang sesuai. Hasil pelatihan diperoleh temuan bahwa:

a. Guru-guru belum mengetahui rambu lalu lintas apasaja yang harus ada dalam taman lalu lintas yang akan dibuat. Pembelajaran mengenalkan rambu dan etika berlalu lintas ini sesuai dengan peraturan pemerintah tentang pentingnya anak mengenal perilaku yang baik dan benar dalam berlalu lintas yakni Peraturan Gubernur Daerah Istimewa Yogyakarta Nomor 54 Tahun 2011 Tentang Pendidikan Etika Berlalu Lintas Pada Satuan Pendidikan Dengan Rahmat Tuhan Yang Maha Esa.

b. Guru-guru yang disekolahnya sudah memiliki taman lalu lintas secara permanen ataupun yang baru merancang pembuatan taman lalu lintas masih kebingungan menggunakan taman lalu lintas dalam pembelajaran selain mengenalkan rambu dan etika berlalu lintas. Kebingungan yang dialami guru ini sesuai dengan hasil penelitian Ika Budi Maryatun dkk tahun 2018 tentang pengembangan buku panduan pembuatan dan dan pelaksanaan pembelajaran di Taman Lalu Lintas.

c. Guru-guru masih kesulitan dalam rancangan pembelajaran di Taman Lalu lintas untuk tema-tema maupun kegiatan selain pengenalan etika dan rambu lalu lintas. Kesulitan ini sesuai dengan hasil penelitian Martha Christianti dkk tahun 2018.

\section{SIMPULAN}

Pelatihan Penggunaan Buku Panduan Pembuatan Dan Pelaksanaan Pembelajaran Di Taman Lalu Lintas Untuk Taman Kanak-Kanak Bagi Guru TK Di DIY mencapai target yang diharapkan yaitu kehadiran peserta melebihi target yaitu dari target 25 menjadi 35, guru-guru dapat menggunakan taman lalu lintas dalam pembelajaran di sekolah, guru-guru dapat mengenalkan rambu lalu lintas dan etika berlalu lintas pada anak melalui penjelasan dengan gambar dan praktik langsung dengan bermain peran, serta guru dapat mengajak anak untuk belajar ditaman lalu lintas dalam tema pembelajaran yang lain seperti Pekerjaan, Lingkungan. Pelatihan ini akan lebih berhasil jika ada praktik yang lebih banyak dalam penyusunan rencana pembelajaran khususnya untuk penggunaaan pembelajaran di taman lalu lintas dalam tema dan kegiatan selain pengenalan rambu dan etika berlalu lintas.

\section{UCAPAN TERIMA KASIH}

Tim mengucapkan terima kasih kepada berbagai pihak yaitu Fakultas Ilmu Pendidikan yang telah memfasilitasi kegiatan melalui dukungan dana DIPA UNY, tim BPP yang telah memberikan masukan, para dosen jurusan PAUD, serta TK-TK yang bersedia bekerjasama dalam pelatihan ini. 
Jurnal Pendidikan Anak, Volume 9 (1), Tahun 2020

Eka Sapti Cahya Ningrum, Martha Christianti, Ika Budi Maryatun, Nur Cholimah

\section{DAFTAR PUSTAKA}

Crain, W. (2007). Teori perkembangan; konsep dan aplikasi; edisi ketiga. Yogyakarta: Pustaka Pelajar.

Dirjen PLS. Direktorat PAUD. (2009). Pedoman penerapan pendekatan "beyond centers and circles time (bcct)" (pendekatan sentra dan saat lingkaran) dalam pendidikan anak usia dini. Jakarta: Depdiknas.

Papalia, D.E., Old, S.W., Feldman, R.D. (2008). Human developmant $9^{\text {th }}$ edition, (psikologi perkembangan, terjemahan oleh A. K. Anwar, Jakarta: Kencana.

Sue Dockett, S. \& Fleer, M. (2002). Play and pedagogy in early childhood, bending the rules, Australia: Thomson.

Sujiono, Y.N. (2013). Konsep dasar pendidikan anak usia dini. Jakarta: Permata Puri Media.

Suyanto, S. (2005). Dasar-dasar pendidikan anak usia dini. Yogyakarta: Hikayat. 